\title{
Functionally Graded Alumina/Mullite Coatings for Protection of Silicon Carbide Ceramic Components from Corrosion
}

\author{
Semi-Annual Report \\ September 1, 1996 - February 1, 1997 \\ By
Stratis V. Sotirchos
RECEIVED MAR O 21999 \\ OSTI
}

Work Performed Under Contract No.: DE-FG22-96PC96208

For

U.S. Department of Energy

Office of Fossil Energy

Federal Energy Technology Center

P.O. Box 880

Morgantown, West Virginia 26507-0880

By

University of Rochester

Department of Chemical Engineering

Rochester, New York 14627 


\section{Disclaimer}

This report was prepared as an account of work sponsored by an agency of the United States Government. Neither the United States Government nor any agency thereof, nor any of their employees, makes any warranty, express or implied, or assumes any legal liability or responsibility for the accuracy, completeness, or usefulness of any information, apparatus, product, or process disclosed, or represents that its use would not infringe privately owed rights. Reference herein to any specific commercial product, process, or service by trade name, trademark, manufacturer, or otherwise does not necessarily constitute or imply its endorsement, recommendation, or favoring by the United States Government or any agency thereof. The views and opinions of authors expressed herein do not necessarily state or reflect those of the United States Government or any agency thereof. 


\section{DISCLAIMER}

Portions of this document may be illegible in electronic image products. Images are produced from the best available original document. 


\section{EXECUTIVE SUMMARY}

The main objective of this research project is the formulation of processes that can be used to prepare compositionally graded alumina/mullite coatings for protection from corrosion of silicon carbide components (monolithic or composite) used or proposed to be used in coal utilization systems (e.g., combustion chamber liners, heat exchanger tubes, particulate removal filters, and turbine components) and other energy-related applications. Mullite will be employed as the inner (base) layer and the composition of the film will be continuously changed to a layer of pure alumina, which will function as the actual protective coating of the component. Chemical vapor deposition reactions of silica, alumina, and aluminosilicates (mullite) through hydrolysis of aluminum and silicon chlorides in the presence of $\mathrm{CO}_{2}$ and $\mathrm{H}_{2}$ will be employed to deposit compositionally graded films of mullite and alumina. Our studies will include the kinetic investigation of the silica, alumina, and aluminosilicate deposition processes, characterization of the composition, microstructure, surface morphology, and mechanical behavior of the prepared films, and modelling of the various deposition processes.

During the first six months of the project, preparatory work was done on the development of the feed supply system (for mixtures of $\mathrm{AlCl}_{3}, \mathrm{SiCl}_{4}, \mathrm{H}_{2}$ and $\mathrm{CO}_{2}$ ) and effluent treatment section for the CVD system we plan to employ for coating preparation. We conducted a comprehensive literature survey of past work done on the chemical vapor deposition of silica, alumina and aluminosilicates (mullite), and we have started work on the study of thermochemical equilibrium in the $\mathrm{Al} / \mathrm{Si} / \mathrm{Cl} / \mathrm{C} / \mathrm{O} / \mathrm{H}$ system so as to identify the boundaries of the region of the space of operating parameters and conditions where preparation of functionally graded mullite/alumina coatings through CVD from metal chloride, $\mathrm{CO}_{2}$, and $\mathrm{H}_{2}$ is feasible. Since the alumina/mullite films that are proposed to be developed can also be applied to carbon matrix composites provided that a layer that bridges the gap that exists between the thermal expansion coefficient of carbon and that of mullite is employed, experiments were conducted on the preparation of com- 
positionally graded carbon/silicon carbide coatings. Deposition from mixtures of ethylene and methyltrichlorosilane or tetrachlorosilane (silicon tetrachloride) in hydrogen was used for the preparation of $S i C / C$ coatings, and our experiments focused on the study of the occurrence of multiple steady states in the deposition process and the effects of the type of chlorosilane on the deposition rate and the deposit composition and their variation along the length of the reactor. The results showed that when operation is carried out outside the multiplicity region, codeposition of $\mathrm{SiC}$ and $\mathrm{C}$ from ethylene and chlorosilanes is a feasible route for preparation of $S i C / C$ graded coatings. Presentations on the results of this work will be made at the 1997 Annual American Ceramic Society Meeting in Cincinnati in April 1997 and at the CVD 14 in Paris in September 1997. A paper has been accepted for publication in the Proceedings of CVD 14. 
TABLE OF CONTENTS

EXECUTIVE SUMMARY . . . . . . . . . . . . . . . ii

TABLE OF CONTENTS .................. . . . . . .

1. BACKGROUND INFORMATION . . . . . . . . . . . . . 1

2. WORK DONE AND DISCUSSION . . . . . . . . . . . . . 5

BIBLIOGRAPHY .................... 6

APPENDIX: Sotirchos, S.V., Kostjuhin, I., Enhanced Deposition of Carbon from $\mathrm{C}_{2} \mathrm{H}_{4^{-}}$ $\mathrm{H}_{2}$ Mixtures in the Presence of Chlorosilanes, to appear in Proceedings of CVD 14, The Electrochemical Society, Pennington, NJ, 1997. 


\section{BACKGROUND INFORMATION}

Silicon-based ceramic materials are used or being considered for use in a variety of applications related to coal utilization and other energy-related systems. In particular, silicon carbide ( $\mathrm{SiC})$, in monolithic or composite form, exhibits such a unique combination of high thermal shock resistance, high thermal conductivity, high strength, low weight, and high oxidation resistance at elevated temperatures that it appears to be the material of choice for a number of technological applications. These include structural components in advanced coal technologies, such as IGCC (integrated gasification combine cycle) and PFBC (pressurized fluidized-combustion) systems, components of advanced turbine systems (combustor liners and, possibly, turbine blades), parts in piston engines (valves and piston heads), ceramic tubes as heat exchangers in coal-fired boilers and industrial furnaces (glass melting and aluminum remelt operations), and ceramic filters for particulate from hot flue and coal gases.

Like $S i$ itself and other $S i$-based ceramics and intermetallics (silicon nitride $\left(\mathrm{Si}_{3} \mathrm{~N}_{4}\right)$ and molybdenum disilicide $\left(\mathrm{MoSi}_{2}\right)$, for instance), the good oxidation resistance of $\mathrm{SiC}$ at high temperatures is due to the formation of a scale of $\mathrm{SiO}_{2}$, through which the oxidizing agent $\left(\mathrm{O}_{2}\right)$ must diffuse to reach unreacted material. $\mathrm{SiO}_{2}$ has one of the lowest diffusion coefficients of $\mathrm{O}_{2}$ (Jacobson, 1993), and as a result, this passive oxidation process is a slow process. At very high temperatures, formation of gaseous $\mathrm{SiO}$ becomes possible, and the oxidation procéss moves into a phase of active oxidation, where because of absence of a protective scale, the rate of the reaction is very high (Wagner, 1958; Pareek and Shores, 1992; Zheng et al., 1992; Sickafoose and Readey, 1993; Nickel et al., 1993). This pattern of oxidation is qualitatively the same for all $S i$-based materials, but the location of the passive to active oxidation transition boundary on the [oxygen partial pressure, temperature] plane varies with each material (Jacobson, 1993).

In a typical application, there are several trace components present in the combustion environment in addition to fuel and oxygen. Among the most important ones are alkalis $(\mathrm{Na}, \mathrm{K})$, halides $(\mathrm{Cl}, I)$, and sulfur $(S)$. All these pollutants are present in relatively large 
quantities in coal and other solid fuels (waste material, for instance), but even some of the cleanest fuels (such as, unleaded gasoline, commercial aviation fuel, and fuel oils) contain significant amounts of sulfur (0.05-1\%) and alkali compounds (4-20 ppm) (Jacobson, 1993). Sodium and halides may also be introduced in the combustion system through the combustion air, especially if combustion occurs in the vicinity of a marine environment. Corrosive degradation of ceramic components occurs by both gaseous and liquid species formed from the various alkali, halide, and sulfur precursors in the high-temperature environment.

Alkali-induced corrosion through liquid deposition of alkali metal salts and oxide slags is the major mechanism of corrosion. The main corrosive species is $\mathrm{Na}_{2} \mathrm{O}$ (or $\mathrm{K}_{2} \mathrm{O}$ ), formed from sulfites or other salts, which tends to react with the protective scale of $\mathrm{SiO}_{2}$ ) forming liquid sodium silicate species $\left(\mathrm{Na}_{2} \mathrm{O} \cdot x\left(\mathrm{SiO}_{2}\right)\right)$. In contrast to $\mathrm{SiO}_{2}$, this liquid layer is not protective because the diffusion coefficient of oxygen in it is much higher than that in $\mathrm{SiO}_{2}$ and because in the high temperature environment it is carried away from the surface through vaporization. The situation is exacerbated in the presence of moisture since more reactions that lead to formation of $\mathrm{Na}_{2} \mathrm{O}$ become thermodynamically more favorable (Van Roode et al., 1993). This corrosion process is not much different from the hot corrosion of turbine alloys that is observed under $\mathrm{Na}_{2} \mathrm{SO}_{4}$ generating conditions and the corrosion that occurs in $S i C$ heat exchanger tubes when alkali halide fluxes are used in the aluminum remelt industry. Surface recession rates of almost $1 \mathrm{~cm} / \mathrm{yr}$ may be observed under these circumstances (Goldfarb, 1988; Van Roode et al., 1993).

Given the exceptional properties of $\mathrm{SiC}$ and of other silicon-based ceramics but their problematic performance in alkali and sulfur containing environments, a protective coating must be used on surfaces exposed to the combustion environment to protect them from corrosion. For proper performance, such a coating must have good oxidation resistance and chemical stability (up to at least $1300^{\circ} \mathrm{C}$ ), good adherence with the base material, and good tolerance to thermal cycling. Problem-free performance during thermal cycling requires that the chosen material must be such that it yields low residual stress at the interface, and this in turn necessitates that there is a good match between the thermal 
expansion coefficient of the substrate and that of the coating.

Alumina presents very good corrosion resistance against the various corrosive compounds that cause degradation of the silica scale that functions as a protective layer of $S i$-based ceramics (Goldfarb, 1988; Lawson et al., 1993). Under some conditions the presence of $\mathrm{Na}_{2} \mathrm{O}$ in the sodium salt melts can lead to formation of an $\beta / \beta^{\prime \prime}$-alumina (Van Hoek et al., 1991,1992), but, as it is evidenced from the long-term, stable performance of $\beta^{\prime \prime}$-alumina ceramics as electrolytes in $N a / S$ cells, further reaction between the $\beta / \beta^{\prime \prime}$ alumina and the sulfur and alkali compounds is practically absent (Gordon et al., 1992). Its high corrosion resistance combined with its relatively low cost makes alumina an ideal candidate as protective coating for silicon carbide, but the problem is that its thermal expansion coefficient is almost twice as large as that of the latter.

In such intractable problems such as joining dissimilar materials (metals and ceramics) and depositing adherent and crack-free films and coatings on substrates having significantly different thermal expansion coefficients, compositionally graded materials (CGM's) provide practical solutions (Ford and Stangle, 1993). In graded materials the composition is varied continuously or in steps between those of two outermost layers. The continuous change in the composition and, hence, microstructure of CGM's results in gradients in their properties, and this makes possible to develop coherent structures that present considerably different properties at the two ends of their thickness. Of particular interest for application to protective coatings is the ability of CGM's to bridge the difference in the thermal expansion coefficients of a base layer, which adheres well to the substrate and matches well its thermal expansion coefficient, and of an outer layer, which exhibits the desired properties of chemical stability and corrosion resistance. By spreading the mismatch of the thermal expansion coefficient over a finite thickness, the local thermal stresses - compressive or tensile depending on which thermal expansion coefficient is larger and in which direction the temperature is changed - are reduced and excessive damage to the coating is avoided (Ford and Stangle, 1993).

It is practically impossible to find a single material that matches the thermal expansion 
coefficient of the substrate material ( $\mathrm{SiC}$ for our studies), adheres well to the substrate, and exhibits good oxidation resistance in the presence of alkali, sulfur, and halogen compounds. Good oxidation resistance more or less requires that the coating be an oxide, but going through a database of thermal expansion coefficients of oxide ceramics, one soon comes to the realization that there is no oxide that both has thermal expansion coefficient matching that of $\mathrm{SiC}$ over the whole temperature range and provides acceptable protection against oxidation and corrosion. There is relatively good agreement between the thermal expansion coefficient of mullite and $S i C$, but, even though mullite does not contain free silica, there is some evidence in the literature that it tends to form sodium aluminosilicates and silicates in an alkali and sodium environment (Dietrichs and Krönert, 1982; Van Roode et al., 1993). As we mentioned in the previous section, much better corrosion resistance is displayed by alumina, but its thermal expansion coefficient is almost a factor of 2 greater than that of $S i C$. The above discussion points to the conclusion that a solution to the problem is offered by a compositionally graded structure, in which the composition varies smoothly between a base layer of mullite, used to provide good adhesion and matching of the thermal expansion coefficient, and an outer layer of alumina, which protects the substrate against corrosion and oxidation.

To reduce the mismatch between alumina and silicon carbide substrates, Federer et al. (1989) and Van. Roode et al. (1993) produced graded coatings with composition varied in $25 \%$ steps between that of mullite (inner layer) and alumina (outer coating) using a plasma spraying method. Their corrosion tests showed that the mullite-alumina graded structures did very well during thermal cycling, showing no visible damage and developing only a few cracks. However, examination of the substrate-coating interface revealed the presence of sodium aluminosilicates $\left(\mathrm{Na}_{2} \mathrm{O} \cdot \mathrm{Al}_{2} \mathrm{O}_{3} \cdot \mathrm{SiO}_{2}\right)$ and, possibly, sodium silicates. Their conclusions were that the problem lied in the porosity $(10-15 \%)$ of the coating produced by plasma spraying and that denser coatings were needed for successful application of the graded coating concept.

The development of processing routes for the fabrication of mullite/alumina graded 
ceramic coatings through chemical vapor deposition (CVD) methods is the subject of the present research proposal. Silica and alumina will be deposited using mixtures of their chlorides with $\mathrm{H}_{2}$ and $\mathrm{CO}_{2}$, and the composition of the deposit will be varied normal to the surface by changing the temperature, pressure, or composition of the gas phase. Experimental deposition studies will be carried out in a hot-wall reactor coupled with a thermogravimetric analysis system, which has already been used successfully in our laboratory to study $\mathrm{SiC}$ deposition from methyltrichlorosilane. Detailed kinetic models of the deposition processes of silica, alumina and mullite will be developed along the general lines of the procedures we used to do so for $\mathrm{SiC}$ deposition. These models will be used for data analysis and process scale-up. The deposits will be characterized by a variety of methods (XRD, Raman spectroscopy, electron microscopy, EDX, and electron microprobe analysis) and will be tested for corrosion using various procedures.

\section{WORK DONE AND DISCUSSION}

During the six months of this reporting period, we accomplished the following: Preparatory work was done on the development of the feed supply system (for mixtures of $\mathrm{AlCl}_{3}, \mathrm{SiCl}_{4}, \mathrm{H}_{2}$ and $\mathrm{CO}_{2}$ ) and effuent treatment section for the CVD system we plan to employ for coating preparation. A comprehensive literature survey of past work done on the chemical vapor deposition of silica, alumina and aluminosilicates (mullite) was carried out, and work was initiated on the study of thermochemical equilibrium in the $\mathrm{Al} / \mathrm{Si} / \mathrm{Cl} / \mathrm{C} / \mathrm{O} / \mathrm{H}$ system so as to identify the boundaries of the region of the space of operating parameters and conditions where preparation of functionally graded mullite/alumina coatings through CVD from metal chloride, $\mathrm{CO}_{2}$, and $\mathrm{H}_{2}$ is feasible. Since the alumina/mullite films that are proposed to be developed can also be applied to carbon matrix composites provided that a layer that bridges the gap that exists between the thermal expansion coefficient of carbon and that of mullite is employed, experiments were conducted on the preparation of compositionally graded carbon/silicon carbide coatings.

Deposition from mixtures of ethylene and methyltrichlorosilane or tetrachlorosilane (silicon tetrachloride) in hydrogen was used for the preparation of $\mathrm{SiC} / \mathrm{C}$ coatings, and 
our experiments focused on the study of the occurrence of multiple steady states in the deposition process and the effects of the type of chlorosilane on the deposition rate and the deposit composition and their variation along the length of the reactor. The results showed that when operation is carried out outside the multiplicity region, codeposition of $\mathrm{SiC}$ and $\mathrm{C}$ from ethylene and chlorosilanes is a feasible route for preparation of $\mathrm{SiC} / \mathrm{C}$ graded coatings. Presentations on the results of this work will be made at the 1997 Annual American Ceramic Society Meeting in Cincinnati in April 1997 and at the CVD 14 in Paris in September 1997. A paper has been accepted for publication in the Proceedings of CVD 14. This paper is attached as an appendix to this report.

\section{BIBLIOGRAPHY}

Dietrichs, P., Krönert, W., INTERCERAM.NR. 3, 223 (1982).

Ford, R.G., Stangle, G.C., Proc. 6th Conf. Cer. Matrix Comp., p. 795, 1993.

Federer, J.I., van Roode, M., Price, J.R., Surface and Coatings Technology, 39/40, 71 (1989).

Goldfarb, V., GRI Contract No. 5086-232-1274, Final Report, 1988.

Gordon, R.S., Heavens, S.N., Virkar, A.V., Weber, N., Corrosion Science, 33, 605 (1992). Jacobson, N.S., J. Amer. Cer. Soc., 76, 3 (1993).

Lawson, M.G., Pettit, F.S., Blachere, J.R., J. Mater. Res., 8, 1964 (1993).

Nickel, K.G., Fu, Z., Quirmbach, P., Trans. ASME, 115, 76 (1993).

Pareek, V.K., Shores, D.A., Science, 48, 983 (1992).

- Sickafoose, R.R., Jr., Readey, D.W., J. Am. Cer. Soc., 76, 316 (1993).

Van Hoek, J.A.M., van Loo, F.J.J., Metselaar, R., Key Eng. Materials, 53-55, 111 (1991).

Van Hoek, J.A.M., van Loo, F.J.J., Metselaar, R., J. Am. Cer. Soc., 75, 109 (1992).

Van Roode, M., Price, J.R., Stala, C., J. Eng. Gas Turb. Power, 115, 139 (1993).

Wagner, C., J. Appl. Physics, 29, 1295 (1958).

Zheng, Z., Tressler, R.E., Spear, K.E., Corrosion Science, 33, 545 (1992). 


\title{
ENHANCED DEPOSITION OF $C$ FROM $C_{2} H_{4}-H_{2}$ MIXTURES IN THE PRESENCE OF CHLOROSILANES
}

\author{
Stratis V. Sotirchos and Igor M. Kostjuhin
}

\author{
Dept. of Chemical Engineering, University of Rochester, \\ Rochester, NY 14627, U.S.A.
}

\begin{abstract}
The deposition of carbon from ethylene in the presence of methyltrichlorosilane or tetrachlorosilane is investigated in this study. Experiments are carried out in a hot-wall tubular reactor coupled to a microbalance for continuous monitoring of the reaction rate. Thin graphite plates and refractory wires are employed as deposition substrates. The experimental results show that the presence of chlorosilane species in the gas phase can lead to rates of carbon deposition that can be by more than an order of magnitude higher than those seen at the same concentration of ethylene in the absence of chlorosilanes. The silicon precursors lead to silicon carbide incorporation in the deposit, its extent depending on the relative concentrations of carbon and silicon bearing species in the gas phase. A kinetic mechanism that may explain the catalytic effect of chlorosilanes on carbon deposition from ethylene is discussed.
\end{abstract}

\section{INTRODUCTION}

Deposition of pyrolytic carbon from the gas phase finds use in a number of applications, such as the fabrication of carbon matrix composites for aerospace and other structural composite applications by chemical vapor infiltration and the preparation of pyrolytic carbon interphases in $\mathrm{SiC}-\mathrm{SiC}$ composites so as to improve their mechanical properties. Mixtures of hydrocarbons and hydrogen are commonly employed as source gases, with methane being the most commonly used hydrocarbon. Because of its practical importance, the deposition of pyrolytic carbon has been the subject of a very large number of studies, and several reviews and monographs have been presented on its chemistry and the properties of the deposited carbon $[1,2,3]$.

In past studies [4], aiming at the formulation of processing schemes for the preparation of functionally graded films and coatings consisting of carbon and silicon carbide for the protection of carbon-carbon composites from oxidation, we conducted an experimental study of the codeposition of $\mathrm{C}$ and $\mathrm{SiC}$ from mixtures of methyltrichlorosilane $\left(\mathrm{CH}_{3} \mathrm{SiCl}_{3}, \mathrm{MTS}\right)$ and ethylene in hydrogen. Chemical vapor deposition experiments were done on graphite substrates in a hot-wall reactor, coupled to a microbalance. The results led to the conclusion that codeposition of $\mathrm{C}$ and $\mathrm{SiC}$ from $\mathrm{C}_{2} \mathrm{H}_{4}-\mathrm{MTS}-\mathrm{H}_{2}$ is a feasible route for the production of functionally graded $\mathrm{SiC} / \mathrm{C}$ films and coatings. Among the most interesting observations made in [4] was that the presence of $M T S$ leads to excess carbon deposition rates that can be more than an order of magnitude higher than the rate that is seen in mixtures of $\mathrm{C}_{2} \mathrm{H}_{4}$ and $\mathrm{H}_{2}$ at the same conditions. The kinetic modelling of the decomposition of MTS in the presence of $\mathrm{H}_{2}[5,6]$ had revealed that the $\mathrm{CH}_{3}$ radicals formed in the first step of the decomposition of $M T S$ are quickly transformed to $\mathrm{CH}_{4}$ and other stable species, and thus, we were led to postulate that the enhancement in the rate of $C$ deposition by the presence of $M T S$ was caused by carbon deposition steps involving surface silicon and carbon species. 
To test this conclusion, chemical vapor deposition experiments were conducted in this study using in addition to $M T S$ a chlorosilane that does not contain carbon and, therefore, does not yield carbon-bearing radicals upon decomposition, namely tetrachlorosilane $\left(\mathrm{SiCl}_{4}\right)$. A detailed description of the experimental system that we employed for deposition experiments can be found in [7]. It combines a vertical, tubular, hot-wall reactor with a sensitive microbalance (Cahn 101), having $1 \mu \mathrm{g}$ sensitivity, and it thus allows for continuous monitoring of the deposition rate. The reactor was a quartz tube with $1.5 \mathrm{~cm}$ internal diameter surrounded by a resistance furnace which provided an almost isothermal zone of about $20 \mathrm{~cm}$. The leading edge of the heating zone almost coincided with the beginning of the isothermal zone of the reactor.

All results we present and discuss were obtained at $1075^{\circ} \mathrm{C}$ temperature in the isothermal zone (set point) and 100 Torr total pressure. Mass flow controllers were used to set and monitor the flow rates of all components of the gaseous mixture, which entered the chemical reactor from the top. Electron microscopy and Energy Dispersive X-Ray (EDX) analysis were employed to examine the morphology and analyze the composition of the deposits. Thin graphite substrates $(0.6 \mathrm{~cm} \times 1.2 \mathrm{~cm})$ hung from thin refractory wires were used to monitor the deposition rate at various locations in the chemical reactor. To obtain a complete picture of the variation of the deposition rate and of the deposit composition with the position in the reactor from a single experiment, deposition experiments were also done on thin molybdenum wires placed along the axis of the reactor. Multiple thick layers were deposited on each wire at different conditions. The deposition rate and the deposit composition were determined by encasing sections of the wires in epoxy resin and applying electron microscopy and EDX to polished cross sections.

\section{RESULTS}

Figure 1 presents the variation of the total deposition rate, expressed in $\mu \mathrm{m} / \mathrm{min}$, with the position in the reactor for $5 \% \mathrm{SiCl}_{4}$ in the feed and $\mathrm{C}_{2} \mathrm{H}_{4}$ feed mole fractions ranging from 0.2 to 0.5 . The corresponding results for the composition of the deposit, expressed as per cent silicon on an atomic basis, are given in Figure 2. The zero value for the distance corresponds to the top edge of the heating zone. Deposition rates from mixtures of only ethylene and hydrogen are also shown in Figure 1 for comparison. It is seen that a dramatic enhancement in the overall deposition rate is caused at all locations in the deposition reactor by the addition of $\mathrm{SiCl}_{4}$ to the reacting mixture. The deposit composition results that are displayed in Figure 2 show that the silicon content of the deposit is around $5 \%$ at all positions, and this, along with the fact that the deposits exhibited no detectable porosity, indicates that most of the increase in the deposition rate is due to enhanced deposition of carbon. In the 5$10 \mathrm{~cm}$ region, where the deposit composition results for different $\mathrm{C}_{2} \mathrm{H}_{4}$ concentrations are not very close to each other, it can be seen that the silicon content of the deposit exhibits a small increase with increasing $\mathrm{C}_{2} \mathrm{H}_{4}$ mole fraction. The overall deposition rate increases strongly with increasing mole fraction of $\mathrm{C}_{2} \mathrm{H}_{4}$ in the feed, and this in conjunction with the weak variation of the $\mathrm{SiC}$ content of the deposit leads us to conclude that the increase in the concentration of the hydrocarbon in the feed has a positive effect of the deposition rates of both $S i C$ and $C$. Apparently, this effect is relatively stronger for the deposition of $S i C$ in the middle part of the isothermal zone of the reactor.

The deposition rate increases monotonically with increasing distance from the entrance of the reactor both in the presence and absence of $\mathrm{SiCl}_{4}$, except close to the lower end of the isothermal zone where it drops sharply as a result of the decrease that the temperature undergoes there. This behavior is at variance with that seen in 
Figures 3 and 4 for codeposition of $\mathrm{SiC}$ and $\mathrm{C}$ from $\mathrm{MTS}-\mathrm{H}_{2}-\mathrm{C}_{2} \mathrm{H}_{4}$ mixtures. These figures present composition and deposition rate profiles in the reactor for $6 \%$ and $12 \%$ $M T S$ in the feed (on a molar basis), respectively, for two values of $\mathrm{C}_{2} \mathrm{H}_{4}$ mole fraction, lying in the 0.1 to 0.5 range. Significant qualitative and quantitative differences are seen to exist not only between the results of Figure 1 and those of Figures 3 and 4 , but also between the results for different $\mathrm{C}_{2} \mathrm{H}_{4}$ concentration in the feed for the same reaction conditions in Figures 3 and 4 . The deposition rate profiles for small $\mathrm{C}_{2} \mathrm{H}_{4}$ mole fraction values present a pronounced maximum close to the entrance of the reactor followed by a decline in two steps to a low value that varies slowly with the distance. As the $\mathrm{C}_{2} \mathrm{H}_{4}$ mole fraction is increased, the maximum is pushed away from the entrance of the reactor, whereas the magnitudes of the successive declines that the deposition rate undergoes are diminished. The results for $50 \% \mathrm{C}_{2} \mathrm{H}_{4}$ in Figure 3 and $45 \% \mathrm{C}_{2} \mathrm{H}_{4}$ in Figure 4 indicate that this eventually leads to disappearance of the maximum and monotonic variation of the deposition rate with the distance in the isothermal part of the reactor. Significant differences are also seen to exist between the deposit composition profiles obtained with $M T S$ in the feed and those shown in Figure 2 for $\mathrm{SiCl}_{4}$. The composition of the deposit exhibits strong variation over the length of the reactor, changing from one of high $\mathrm{SiC}$ content close to the entrance to a composition of about $5-10 \% S i$ in the lower part of the isothermal zone, a value that is close to that obtained with $\mathrm{SiCl}_{4}$ in the feed over the whole length of the reactor (see Figure 2).

The behavior seen in Figures 1 and 2 for the variation of the deposition rate with the length of the reactor is not representative of the behavior of the $\mathrm{SiCl}_{4}-\mathrm{C}_{2} \mathrm{H}_{4}-\mathrm{H}_{2}$ system for $\mathrm{C}_{2} \mathrm{H}_{4}$ mole fraction lower than 0.1 . For such $\mathrm{C}_{2} \mathrm{H}_{4}$ mole fraction values, preliminary experiments have shown that the deposition rate and composition profiles behave more like those for the $M T S-C_{2} H_{4}-H_{2}$ system in Figures 3 and 4 for small values of $\mathrm{C}_{2} \mathrm{H}_{4}$ mole fraction. Some of the results obtained in these experiments are shown in Figure 5 which examines the effect of the introduction of $\mathrm{C}_{2} \mathrm{H}_{4}$ in the feed on the deposition rate from $M T S-H-2$ and $\mathrm{SiCl}_{4}-\mathrm{H}_{2}$ mixtures. Deposition experiments for the two chlorosilanes were carried out at the same reaction conditions $\left(1075^{\circ} \mathrm{C}\right.$, 100 Torr, and $200 \mathrm{cc} / \mathrm{min}$ ) and similar silane concentrations $(6 \% M T S$ vs. $5 \%)$ and locations in the deposition reactor $(3.5$ vs. $2.5 \mathrm{~cm}$ ). Qualitatively similar variation of the deposition rate with the $\mathrm{C}_{2} \mathrm{H}_{4}$ mole fraction is observed in the results of Figure 1 for the two chlorosilanes. Addition of $\mathrm{C}_{2} \mathrm{H}_{4}$ leads to a steep rise in the deposition rate in both cases. As the $\mathrm{C}_{2} \mathrm{H}_{4}$ mole fraction is increased, the deposition rate first goes through a maximum, and it subsequently drops to a minimum value within a small range of $\mathrm{C}_{2} \mathrm{H}_{4}$ mole fraction. Beyond the minimum, it increases almost linearly with the $\mathrm{C}_{2} \mathrm{H}_{4}$ mole fraction. For $\mathrm{SiCl}_{4}$, the range of linear variation corresponds to the range of $\mathrm{C}_{2} \mathrm{H}_{4}$ mole fraction values examined in Figure 1 , and this is why no local extrema are observed in this figure in the variation of the deposition rate with the distance in the reactor.

For small and moderate amounts of carbon present in the deposit, X-Ray Diffraction analysis revealed the presence of $\beta-S i C$ and amorphous carbon. For large amounts of carbon in the deposit, no crystalline phases could be detected by XRD. This results is in agreement with a similar observation made by Maury and Agullo [8] for $S i C / C$ deposits prepared by CVD from tetraethylsilane and isopropylbenzene mixtures. The photomicrographic examination of fracture surfaces of the deposits did not reveal he presence of porosity. An electron micrograph showing the free surface and fracture surface of a film prepared from $M T S-C_{2} H_{4}-H_{2}$ mixture at the conditions of Figure 5 with $50 \% C_{2} H_{4}$ in the feed is shown in Figure 6. Electron micrographs of the free surface of two films at a larger magnification are shown in Figures 7 and 8. 
These films were again prepared at the conditions of Figure 5 from $M T S$ with $2.5 \%$ and $15 \% \mathrm{C}_{2} \mathrm{H}_{4}$ in the feed, respectively. It is seen that as the $\mathrm{C}_{2} \mathrm{H}_{4}$ concentration increases and carbon starts to be incorporated in the deposit, the texture of the surface of the film becomes finer. This was found to be in general the case at all conditions studied in our experiments, both for $M T S$ and $\mathrm{SiCl}_{4}$.

\section{DISCUSSION}

The MTS-C $\mathrm{C}_{2} \mathrm{H}_{4}-\mathrm{H}_{2}$ and $\mathrm{SiCl}_{4}-\mathrm{C}_{2} \mathrm{H}_{4}-\mathrm{H}_{2}$ mixtures that are fed into the chemical reactor- undergo upon exposure to the high temperature environment a series of elementary chemical reactions that lead to formation of a large number of stable and radical chemical species. Some of these species function as the actual precursors for $S i, C$, and $S i C$ deposition on the substrate and other surfaces present in the chemical reactor. Papasouliotis and Sotirchos $[5,6]$ formulated a detailed homogeneous chemistry model for the decomposition of $M T S$ in $\mathrm{H}_{2}$, and the results that were obtained from that model were used, along with those from the analysis of the thermochemical equilibrium of the $M T S-H_{2}$ system, as basis for the formulation of a heterogeneous chemistry model [5] for solid deposition from $M T S-H_{2}$ mixtures. Deposition of $S i$, $C$, and $S i C$ was assumed to occur primarily through the following reaction steps:

$$
\begin{gathered}
{\left[\mathrm{SiCl}_{2}\right]_{s}+\mathrm{H}_{2} \rightleftharpoons \mathrm{Si}+\mathrm{S}+2 \mathrm{HCl}} \\
{\left[\mathrm{CH}_{2}\right]_{s} \rightleftharpoons \mathrm{C}+\mathrm{S}+\mathrm{H}_{2}} \\
{\left[\mathrm{SiCl}_{2}\right]_{s}+\left[\mathrm{CH}_{2}\right]_{s} \rightleftharpoons \mathrm{SiC}+2 \mathrm{~S}+2 \mathrm{HCl}}
\end{gathered}
$$

Brackets with subscript $s$ are used to denote species adsorbed on the surface, and $S$ is used to represent an active site for adsorption.

The results that were obtained from the overall homogeneous and heterogeneous chemistry model showed that this model could provide qualitative, and to certain extent quantitative, explanations for most phenomena observed in experimental studies of solid deposition from $M T S-\mathrm{H}_{2}$ mixtures. Among the most interesting conclusions that were extracted from the analysis of those results was that the deposition of $\mathrm{SiC}$ is chiefly limited by the availability of carbon-bearing species on the deposition surface, which, in turn, is affected by the concentration of hydrocarbons and carbon-bearing radicals with high surface reactivity, such as $\mathrm{C}_{2} \mathrm{H}_{4}$ and $\mathrm{C}_{2} \mathrm{H}_{2}$ [3]. This conclusion is in agreement with the strong positive effect of the addition of $\mathrm{C}_{2} \mathrm{H}_{4}$ on the total rate of deposition from $M T S$ that is observed in the results of Figure 5. The qualitatively similar behavior of the deposition rate from $\mathrm{SiCl}_{4}$ with the increase in the $\mathrm{C}_{2} \mathrm{H}_{4}$ mole fractions suggests that something similar must be happening in that case as well.

Since the $M T S-C_{2} H_{4}-H_{2}$ and $\mathrm{SiCl}_{4}-\mathrm{C}_{2} \mathrm{H}_{4}-\mathrm{H}_{2}$ mixtures involve the same chemical elements as the $M T S-H_{2}$ system, one expects the detailed gas phase and surface chemistry model of Sotirchos and Papasouliotis [5] to be applicable to these mixtures. However, the surface steps that lead to solid deposition (equations (1)-(3)) in that model cannot explain the enhanced deposition of excess carbon in the presence of chlorosilane species. The catalytic effect of the addition of $\mathrm{SiCl}_{4}$ in the feed on the deposition of carbon lends support to the argument made in our previous study that this phenomenon is caused by the deposition of carbon through reaction steps that involve both carbon- and silicon-bearing species. It was postulated in [4] that such a possible step could be

$$
\left[\mathrm{SiCl}_{3}\right]_{s}+[\mathrm{CH}]_{s} \rightleftharpoons \mathrm{C}+\mathrm{S}+\left[\mathrm{SiCl}_{2}\right]_{s}+\mathrm{HCl}
$$

However, there are many other possible steps that can lead to the same effect, such 


$$
\left[\mathrm{SiCl}_{2}\right]_{s}+[\mathrm{CH}]_{s} \rightleftharpoons \mathrm{C}+\mathrm{S}+[\mathrm{SiCl}]_{s}+\mathrm{HCl}
$$

In reaction steps involving silicon-chlorine and carbon-hydrogen species of the type of equations (4) and (5), $\mathrm{HCl}$ appears as a product. This compound is also involved as a product in the reaction steps assumed to lead to deposition of $\mathrm{Si}$ and $\mathrm{SiC}$ (see equations (1) and (3)), and therefore, one would expect the deposition rates of excess carbon, silicon, and silicon carbide, to be adversely affected by the introduction of $\mathrm{HCl}$ in the reactor. Past experimental studies, both by our group and others $[9,10]$, showed that this is indeed the case for $\mathrm{Si}$ and $\mathrm{SiC}$ deposition from $\mathrm{MTS}$ in $\mathrm{H}_{2}$. The kinetic investigation of the codeposition of $\mathrm{SiC}$ and $\mathrm{C}$ from $\mathrm{MTS}-\mathrm{C}_{2} \mathrm{H}_{4}-\mathrm{H}_{2}$ mixtures revealed that $\mathrm{HCl}$ has a strong inhibitory effect of the deposition rates of $\mathrm{SiC}$ and $C$ [4], and this observation was exploited in setting up a processing scheme for the preparation of functionally graded $S i C / C$ films from $M T S$ and $C_{2} H_{4}$ mixtures in hydrogen with composition varying between silicon carbide and carbon. Preliminary experiments revealed that $\mathrm{HCl}$ inhibits in a similar fashion the deposition of $\mathrm{SiC}$ and $\mathrm{C}$ from $\mathrm{SiCl}_{4}-\mathrm{C}_{2} \mathrm{H}_{4}$ mixtures.

In the kinetic studies of solid deposition from $M T S-\mathrm{H}_{2}[7,9]$ and $M T S-\mathrm{C}_{2} \mathrm{H}_{4}-\mathrm{H}_{2}$ [4], it was observed that these deposition processes present multiple steady states, a situation that manifests itself experimentally as more than one stable deposition rates at the same reaction conditions and abrupt changes in the deposit composition and the deposition rate as the operating parameters of the process are varied. Similar behavior has been seen in the deposition of $\mathrm{SiC}$ and $\mathrm{Si}$ from $\mathrm{SiCl}_{4}-\mathrm{C}_{2} \mathrm{H}_{4}-\mathrm{H}_{2}$ mixtures. We believe that the existence of multiple steady states is the cause of the sharp changes that the deposition rate undergoes along the length of the reactor (Figure 1) or as the concentration of $\mathrm{C}_{2} \mathrm{H}_{4}$ is changed (Figure 5). The reaction rate changes in Figures 3 and 4 are accompanied by changes in the deposit composition, and the experimental analysis of the composition of deposits showed that this was also the case for the results of Figure 5. For $\mathrm{SiCl}_{4}$, which does not contain carbon, the initial increase in the deposition rate in Figure 5 is accompanied by a change in the composition of the film from pure silicon to silicon carbide with some free silicon. For MTS, the increase in the deposition rate is due to the enhancement of the deposition rate of silicon carbide by the addition of $\mathrm{C}_{2} \mathrm{H}_{4}$ in the feed. In both cases, the composition of the deposit starts to deviate significantly from that of silicon carbide as $C_{2} H_{4}$ is added in the film only as the range of steep decrease of the deposition rate is approached, with the composition going from almost pure silicon carbide at the maximum to a deposit of high carbon content in the minimum. For MTS, the change of composition takes place for $\mathrm{C}_{2} \mathrm{H}_{4}$ mole fraction going from 0.07 to 0.25 , and therefore, it is possible to obtain compositionally graded films going from $100 \% \mathrm{SiC}$ to about $20 \% \mathrm{SiC}$ by varying the $\mathrm{C}_{2} \mathrm{H}_{4}$ concentration. Doing this for $\mathrm{SiCl}_{4}$ at the conditions of Figure 5 is practically impossible because the change in the deposit composition occurs in a very narrow range of $\mathrm{C}_{2} \mathrm{H}_{4}$ mole fraction.

The much higher rates of $S i C$ and $\mathrm{C}$ deposition from $\mathrm{MTS}$ than from $\mathrm{SiCl}_{4}$ for similar values of $S i$ and $C$ content in the feed, especially close to the entrance of the reactor, as well as the differences that are observed among these two reactive systems in the variation of the deposit stoichiometry and deposition rate along the length of the reactor or with increasing $C_{2} H_{4}$ concentration, are most probably a consequence of the formation of $\mathrm{SiCl}_{3}$ and $\mathrm{CH}_{3}$ radicals from the first step of the decomposition of $M T S$ [11]. These species exhibit high surface reactivity, but as the reactive mixture moves deeper into the reactor, and subsequent reaction steps convert them to less reactive species (e.g., hydrocarbons and $\mathrm{SiCl}_{4}$ ), the chemistry of the overall process gets closer to that of the deposition of $\mathrm{C}$. and $\mathrm{SiC}$ from $\mathrm{SiCl}_{4}-\mathrm{C}_{2} \mathrm{H}_{4}-\mathrm{H}_{2}$ mixtures. 
The enhanced deposition of carbon in the presence of chlorosilanes might be of interest to those working in the area of carbon deposition and, in particular, chemical vapor infiltration. Provided that the incorporation of small amounts of $\mathrm{SiC}$ in the deposit does not affect adversely its mechanical properties and that the increase in the reaction rate is not accompanied by decreased deposition uniformity in the preform, it might be possible to significantly reduce the processing time for carbon matrix composite fabrication by CVI by introducing small amounts of chlorosilane in the hydrocarbon feed. Among the most interesting phenomena displayed by the results of Figures 1, 3, and 4 for CVI applications is that additions of $S i C l_{4}$ (and of $M T S$ for large values of $\mathrm{C}_{2} \mathrm{H}_{4}$ mole fraction) in the feed leads not only to enhancement of the deposition rate of carbon but also to increasing deposition rate along the length of the reactor. Depending on the deposition conditions and the properties of the porous preform, this situation may translate to increasing deposition rate away from the external surface of the preform enabling densification to proceed from the inside out.

\section{ACKNOWLEDGMENTS}

This research was supported by grants from the National Science Foundation and the Department of Energy. The help of Mr. Brian McIntyre with the characterization of the deposits is gratefully acknowledged.

\section{REFERENCES}

1. G. Savage, Carbon-Carbon Composites, Chapman \& Hall, London (1992).

2. H.O. Pierson, Handbook of Carbon, Graphite, Diamond, and Fullerenes: Properties, Processing, and Applications, Noyes Publications, Park Ridge (1993).

3. W.V. Kotlensky, in Chemistry and Physics of Carbon, P.L. Walker, Jr and P.A. Thrower, Editors, Vol. 9, p. 173, Marcell Dekker, Inc., New York (1973).

4. S.V. Sotirchos and I.M. Kostjuhin, in Proceedings of CVD XIII, p. 733, The Electrochemical Society, Pennington, NJ (1996).

5. S.V. Sotirchos and G.D. Papasouliotis, MRS Symp. Proc., 250, 35 (1992).

6. G.D. Papasouliotis and S.V. Sotirchos, J. Electrochem. Soc., 141, 1599 (1994).

7. G.D. Papasouliotis and S.V. Sotirchos, J. Electrochem. Soc., 142, 3834 (1995).

8. F. Maury and J.M. Agullo, Surface and Coatings Technol., 76-77, 119 (1995).

9. G.D. Papasouliotis and S.V. Sotirchos, in Proceedings of CVD XIII, p. 645, The Electrochemical Society, Pennington, NJ (1996).

10. F. Loumagne, Ph.D. Thesis, University of Bordeaux I, Bordeaux, France (1993).

11. M.D. Allendorf, C.F. Melius, and T.H. Osterheld, in Proceedings of CVD XII, p. 20, The Electrochemical Society, Pennington, NJ (1993). 


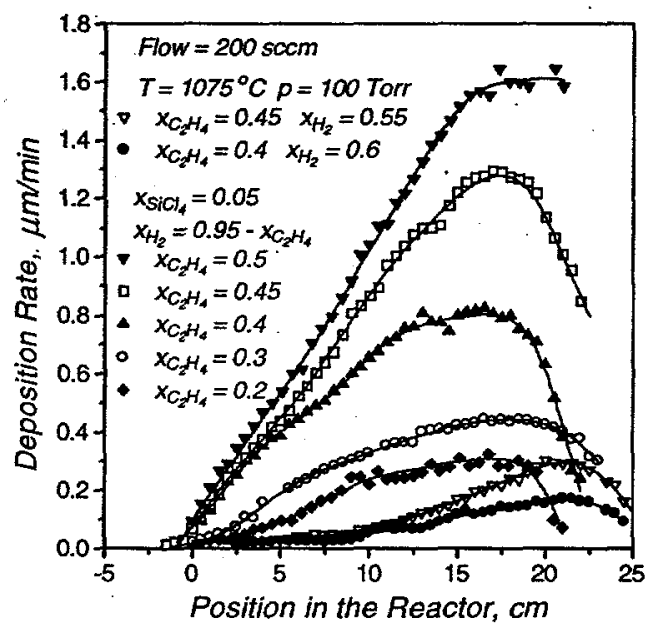

Figure 1. Variation of the deposition rate with the position in the reactor in the presence of $\mathrm{SiCl}_{4}$.

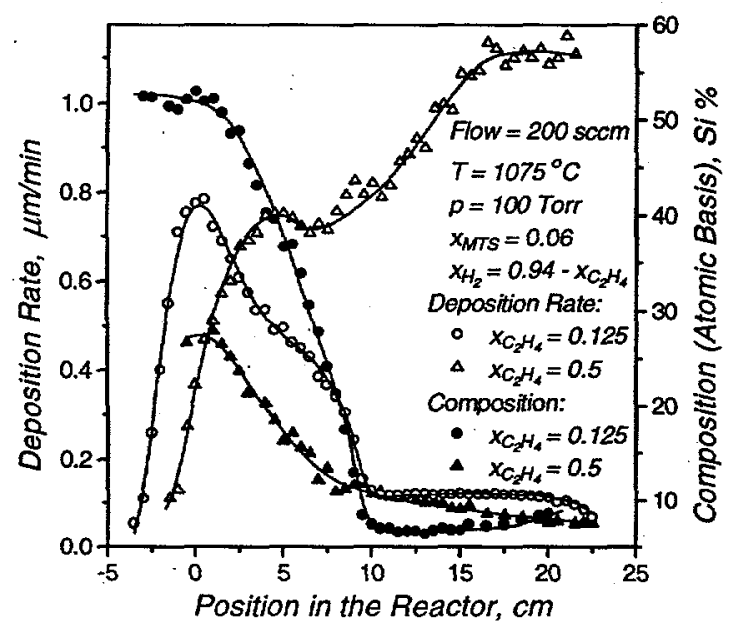

Figure 3. Variation of the deposition rate and of the deposit stoichiometry with the position in the reactor in the presence of $M T S$.

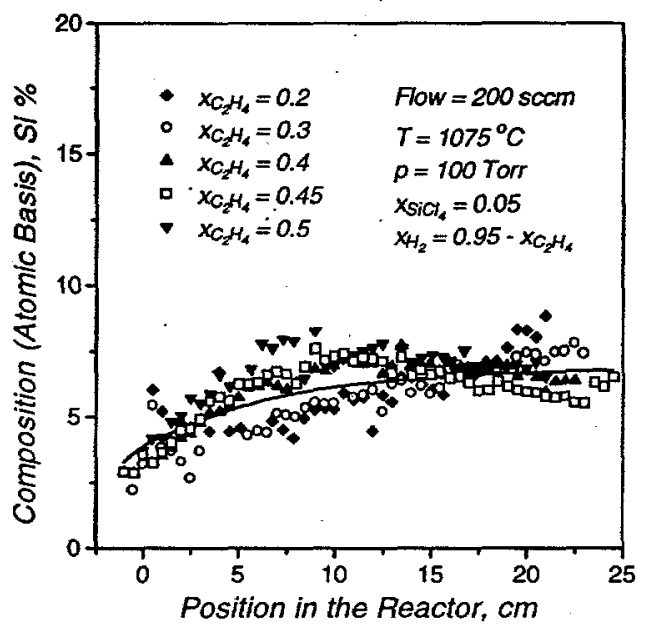

Figure 2. Variation of the deposit stoichiometry with the position in the reactor in the presence of $\mathrm{SiCl}_{4}$.

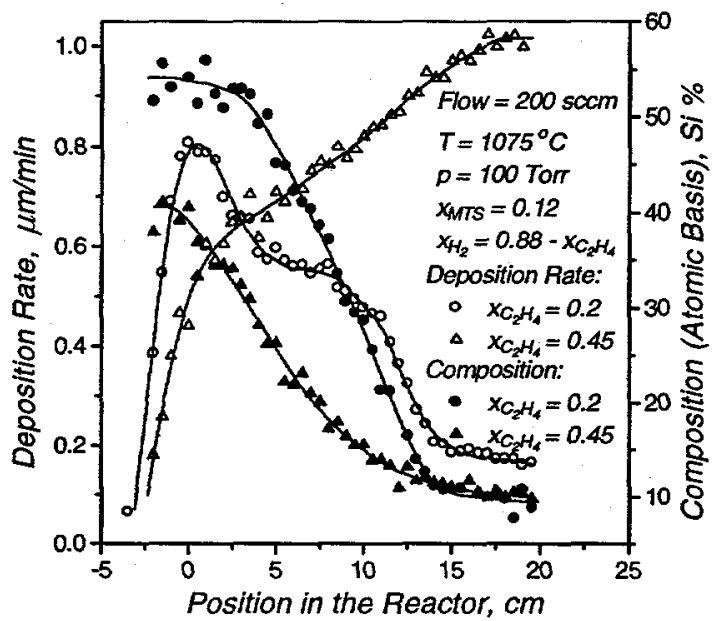

Figure 4. Variation of the deposition rate and of the deposit stoichiometry with the position in the reactor in the presence of $M T S$. 


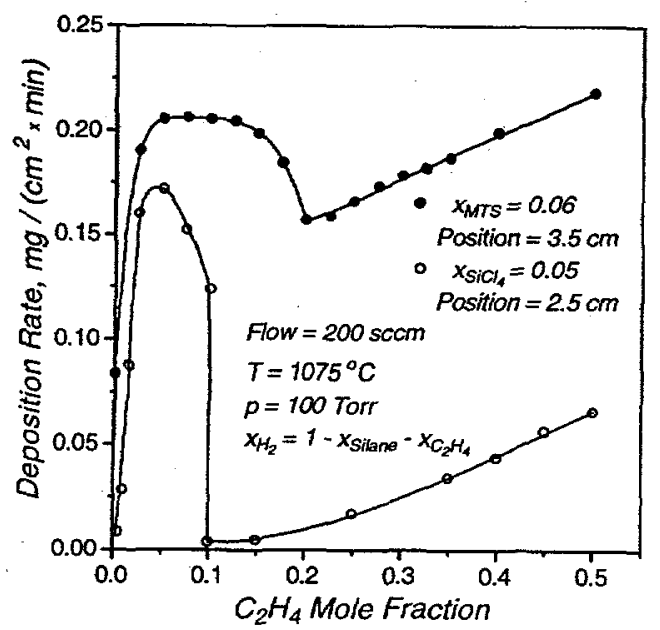

Figure 5. Deposition rate vs. $\mathrm{C}_{2} \mathrm{H}_{4}$ mole fraction for $S i C l_{4}$ or $M T S$ present in the feed.

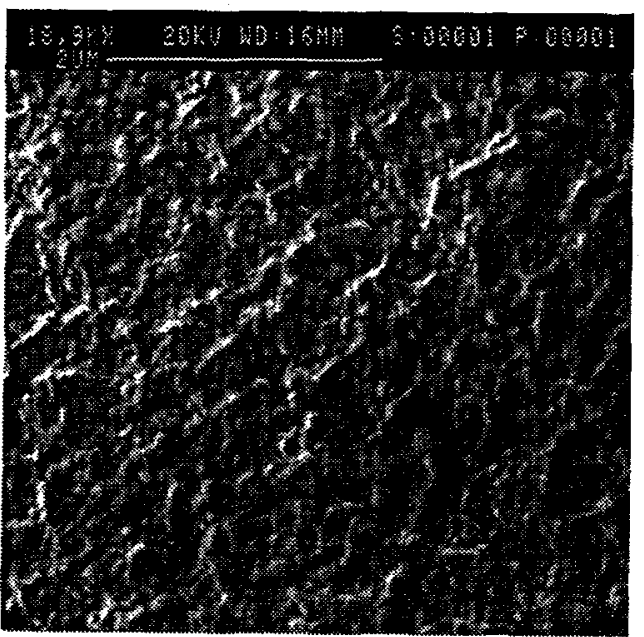

Figure 7. Electron micrograph of the surface of a film prepared at the conditions of Figure 5 with $M T S$ and $2.5 \%$ $\mathrm{C}_{2} \mathrm{H}_{4}$ in the feed.

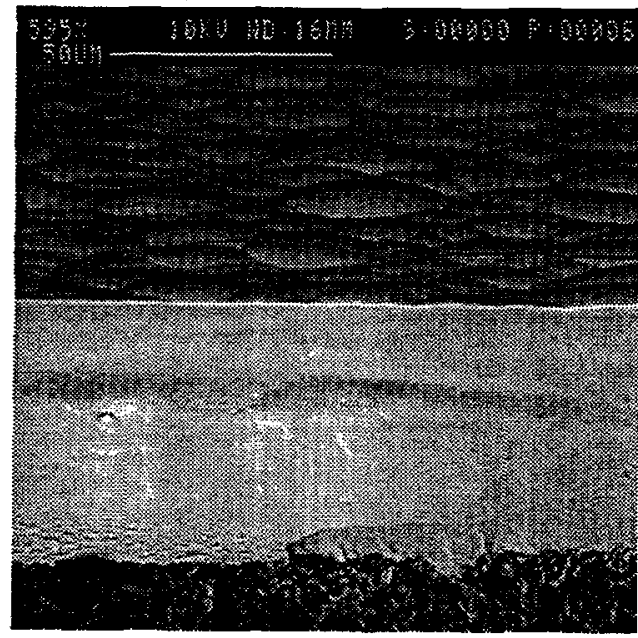

Figure 6. Electron micrograph of the fracture edge of a film prepared at the conditions of Figure 5 with $M T S$ and $50 \% \mathrm{C}_{2} \mathrm{H}_{4}$ in the feed.

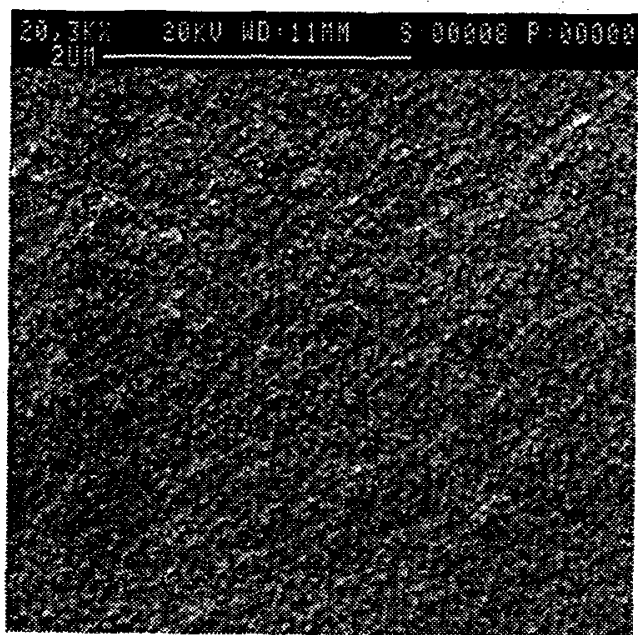

Figure 8. Electron micrograph of the surface of a film prepared at the conditions of Figure 5 with $M T S$ and $15 \%$ $\mathrm{C}_{2} \mathrm{H}_{4}$ in the feed. 